\title{
A two-locus model for the joint estimation of intergametophytic and intragametophytic selfing rates
}

\author{
Kermit Ritland, \\ Douglas E. Soltis $\dagger$ and \\ Pamela S. Soltis $\dagger$
}

\author{
* Department of Botany, University of Toronto, \\ Toronto, Ontario M5S 3B2, Canada. \\ $\dagger$ Department of Botany, Washington State University, \\ Pullman, Washington 99164, U.S.A.
}

Inbreeding in homosporous plants, unlike angiosperms, can consist of two potential components: (1) fusion of gametes from the same gametophyte (intragametophytic selfing) and (2) matings between different gametophyte of the same parent (intergametophytic selfing). Although some workers maintain that intragametophytic selfing predominates in these populations, no attempt has been made to evaluate these two components of inbreeding in natural populations of homosporous ferns or lycopods. This paper gives a method for joint estimation of these two selfing rates, which uses data from two unlinked loci and makes the assumption of inbreeding equilibrium. The procedure was used to estimate selfing rates in six populations of two fern species. Weakly significant levels of intergametophytic selfing were found in one population of each species. The validity of the assumption of inbreeding equilibrium is discussed, and the requirement for several polymorphic marker loci is emphasized.

\section{INTRODUCTION}

Homosporous cryptograms offer a unique opportunity to study the genetics and evolution of inbreeding (Klekowski, 1979; Hedrick, 1987; D. Soltis and P. Soltis, 1987a). Unlike higher plants, the gametophytes of homosporous pteridophytes are free-living and potentially bisexual, so that sperm and eggs derived from the same gametophyte can fuse, resulting in "intragametophytic" selfing (Klekowski, 1969). This type of selfing produces a completely homozygous diploid sporophyte in a single generation.

Since either allele at a heterozygous locus has an equal chance of becoming homozygous by this process, this type of inbreeding immediately exposes half of the deleterious recessive alleles in the genome. Despite this potential selective disadvantage of intragametophytic selfing, electrophoretic studies have indicated high levels of such selfing in Botrychium (McCauley, Whittier and Reilly, 1985; D. Soltis and P. Soltis, 1987a; Soltis et al., 1988) and Asplenium (Werth, Guttman and Eshbaugh, 1985), and moderate levels in Dryopteris expansa (D. Soltis and P. Soltis, 1987b). Outbreeding seems to occur in most fern species that have been examined (D. Soltis and P. Soltis,
$1987 a$; Soltis et al., 1988), as well as lycopod species (P. Soltis and D. Soltis, 1988b) and Equisetum arvense (D. Soltis et al., 1988).

A second type of inbreeding may also occur in vascular cryptogrms. If different gametophytes derived from the same parent mate with each other, then "intergametophytic" selfing will occur, which is the mode of selfing observed in higher plants. Thus, in homosporous cryptogram populations, the potential exists for three types of matings: (1) intragametophytic selfing, (2) intergametophytic selfing, and (3) random outcrossing (Klekowski, 1969).

It has been argued that intergametophytic selfing is likely to be uncommon in homosporous pteridophytes for two reasons. First, it requires that spore dispersal be limited, such that gametophytes of the same parent establish themselves in sufficiently close proximity for mating to occur. Although no studies have directly estimated local spore dispersal, at least in some habitats it appears to be substantial, based upon indirect evidence such as lack of genetic structure within populations and high gene flow estimates (using the method of Slatkin, 1985) both within and among populations (P. Soltis and D. Soltis, 1987). Second, even if intergametophytic selfing were to be present, it has been assumed that the close 
proximity of male and female gametangia would cause intragametophytic selfing to predominate (Klekowski and Baker, 1966; Klekowski, 1979). However, the presence of intergametophytic selfing in homosporous pteridophytes cannot be ruled out until specific statistical models are designed which can reject its presence.

Workers have inferred the presence of intragametophytic selfing by comparing the frequencies of homozygous vs. heterozygous genotypes at polymorphic marker-gene loci. More precisely, the proportion of intragametophytic selfing is simply estimated as the inbreeding coefficient (the proportion of individuals with alleles "identical-by-descent" at a single locus). This is because the percentage of intragametophytic selfing practised in the previous generation equals the inbreeding coefficient of the current generation (McCauley, Whittier and Reilly, 1985). Many procedures exist for estimating the singlelocus inbreeding coefficient (Nei, 1986; see Holsinger 1987 for an application to intragametophytic selfing).

This inbreeding coefficient is also influenced by any intergametophytic selfing practiced in the population. Unfortunately, the two types of selfing are confounded such that their relative proportions cannot be determined from this single-locus inbreeding coefficient alone. In the absence of other types of information, workers have assumed that intragametophytic selfing is absent. Clearly, other categories of data are needed. One such category consists of the arrays of single-locus progeny genotypes descended from common parents, which was shown by Hedrick (1987) to provide sufficient information to estimate both selfing rates. However, progeny arrays are difficult to collect for homosporous cryptograms, and such data remain unavailable.

This paper considers another category of data for the joint estimation of both types of selfing: genotypic frequencies at two unlinked loci. These frequencies are functions of two-locus inbreeding coefficients, which can detect intergametophytic selfing because one of these coefficients is non-zero only if such selfing is present. Estimation of the relative amounts of both types of selfing requires an assumption of inbreeding equilibrium, i.e., constancy of genotypic frequencies among generations. Analysis of data from Polystichum munitum and Botrychium virginianum illustrate the use of, and the potential problems with, this estimation procedure. At the minimum, multilocus analyses will allow us to accept or reject the presence of intergametophytic selfing.
ESTIMATION OF RATES OF

INTERGAMETOPHYTIC AND

INTRAGAMETOPHYTIC SELFING FROM

GENOTYPIC FREQUENCIES

\section{(i) Estimators based upon two-locus inbreeding coefficients}

Inbreeding coefficients, as compared to genotypic frequencies, provide the most direct means of studying selfing. These coefficients measure the probability that a set of alleles is identical-bydescent (ibd), i.e., copies of the same allele present in some ancestor. This "set" consists of two or more alleles, present in one or more individuals. The simplest inbreeding coefficient is Wright's $F$ (Wright, 1969), defined as the probability that the pair of alleles possessed by a diploid individual at a single locus are ibd.

In a population where a fraction $r$ of adults practice intragametophytic selfing, a fraction $s$ of adults practise intergametophytic selfing, and a remaining fraction $t$ of adults practise random outcrossing $(t=1-r-s)$, simple Mendelian arguments predict that Wright's $F$ of progeny (denoted with a prime) is related to $F$ of adults as

$$
F^{\prime}=r+s\left(\frac{1}{2}+\frac{1}{2} F\right) \text {. }
$$

Note that intragametophytic selfing produces progeny whose alleles are all ibd, while intragametophytic selfing produces progeny with a fraction $(1+F) / 2$ of alleles ibd.

Previous studies of intragametophytic selfing have assumed that intergametophytic selfing is not present, i.e., $s=0$. Indeed, even if intergametophytic selfing were present, it would be impossible to estimate its amount, for inspection of equation (1) reveals that either $r$ or $s$, but not both, can be estimated. All we can do is to note that if $s$ is positive, the estimate of $r$ is biased upwards.

To separate intragametophytic selfing from intergametophytic selfing, the approach adopted here is to consider two unlinked loci and their "two-locus inbreeding coefficients", as originally introduced by Weir (1968). To define these coefficients, consider two diploid loci, wherein four alleles reside. Between these four alleles, four configurations of identity-by-descent exist, as depicted in fig. 1 . When we realize that inbreeding has the same expected effect upon all loci, then the two configurations involving identity at just one of two loci occur wth equal frequency, and just three configurations of identity-by-descent are sufficient to describe inbreeding at two loci.

Thus, at two loci, there are three modes of gene-identity: (1) alleles at both loci not-ibd, (2) 


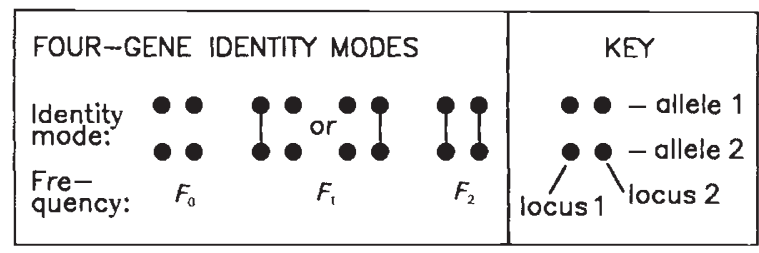

Figure 1 The four possible modes of identity-by-descent between homologous genes at two loci (identical genes are linked by lines).

alleles at one locus ibd and alleles at the other locus not-ibd, and (3) alleles at both loci ibd. The three inbreeding coefficients, which are the frequencies of these configurations, are defined as

$F_{i}=\operatorname{prob}($ two loci have $i$ genes in common)

$$
\left(F_{0}+F_{1}+F_{2}=1,0 \geq F_{i} \leqq 1\right)
$$

(fig. 1). These coefficients are a subset of the "descent measures" developed by Weir and Cockerham (Cockerham and Weir, 1973), whose more complex set of measures includes allelic associations between loci. The single-locus $F$ is related to the two-locus coefficients as $F=\frac{1}{2} F_{1}+F_{2}$.

With fractions of intragametophytic selfing $r$, intergametophytic selfing $s$, and random outcrossing $t$, the inbreeding coefficients of progeny are related to those of adults as

$$
\begin{aligned}
& F_{0}^{\prime}=(1-r-s)+s\left(\frac{1}{4} F_{0}\right) \\
& F_{1}^{\prime}=s\left(\frac{1}{2} F_{0}+\frac{1}{2} F_{1}\right) \\
& F_{2}^{\prime}=r+s\left(\frac{1}{4} F_{0}+\frac{1}{2} F_{1}+F_{2}\right) .
\end{aligned}
$$

We can solve for both $r$ and $s$ in equation (2) as

$$
\begin{aligned}
& s=\left(\frac{2 F_{1}^{\prime}}{F_{0}+F_{1}}\right) \\
& r=F_{2}^{\prime}-\left(\frac{2 F_{1}^{\prime}}{F_{0}+F_{1}}\right)\left(\frac{F_{0}+2 F_{1}+4 F_{2}}{4}\right) .
\end{aligned}
$$

Equation (3) can be used to estimate the joint rates of intragametophytic and intergametophytic selfing, using the estimates of inbreeding coefficients as discussed in section (iii) below.

\section{(ii) Inbreeding equilibrium and the "space" of inbreeding coefficients}

Equation (3) allows inbreeding coefficients to vary over generations. However, for practical purposes we will assume inbreeding equilibrium, or $F_{i}^{\prime}=F_{i}$, which allows us to use genotypic frequencies in the progeny population to represent genotypic frequencies in the adult population.

In a population at inbreeding equilibrium, there is a considerable restriction placed upon the allowable values of the two-locus inbreeding coefficients. One way to study this restriction is to show how the two-dimensional "space" of selfing maps to the two-dimensional "space" of two-locus inbreeding coefficients. Using equation (3), this mapping is shown in fig. 2. Interestingly, many values of inbreeding coefficients are not attainable. This implies that if our estimates of inbreeding

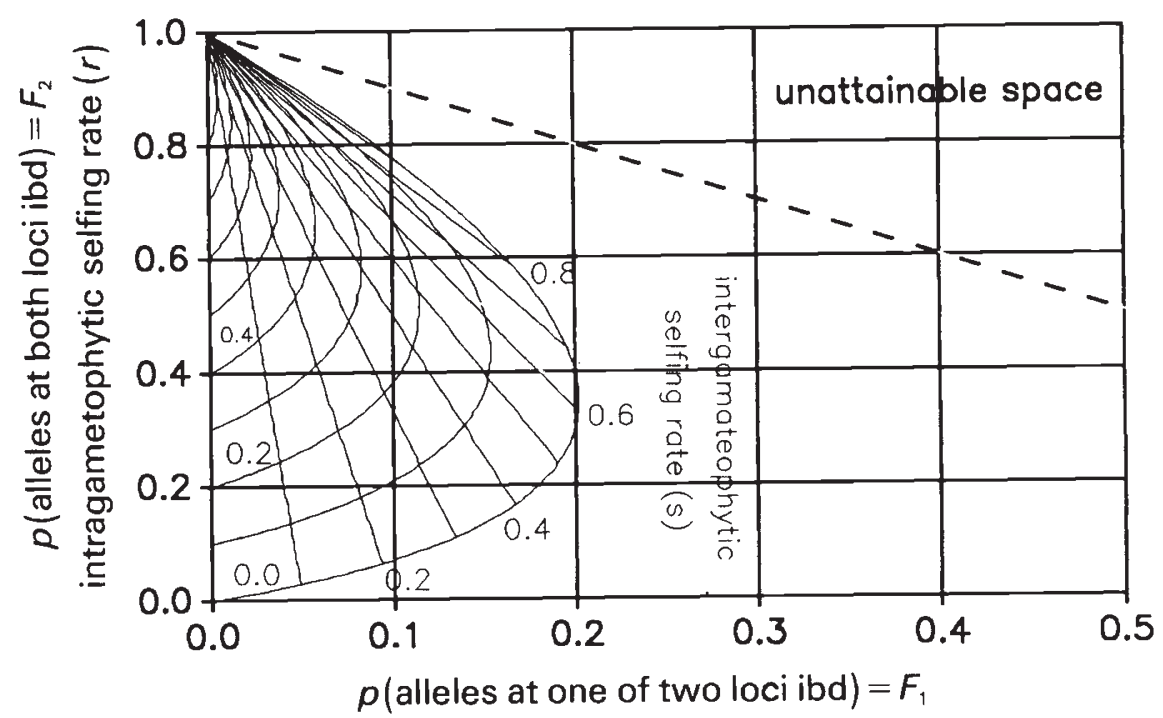

Figure 2 The relationship between two-locus inbreeding coefficients $\left(F_{1}\right.$ and $\left.F_{2}\right)$ and selfing rates $(r$ and $s)$ at inbreeding equilibrium. The two-locus inbreeding coefficients have certain "unattainable" spaces: the region above the dotted line is never attainable, and the region outside the curved lines defining the selfing rates is not attainable at inbreeding equilibrium. 
coefficients lie outside this region, then a violation of model assumptions must have occured. The potential violations include (1) other sources of inbreeding, such as population substructure and biparental inbreeding, and (2) non-equilibrium of inbreeding coefficients.

For populations not at inbreeding equilibrium, the allowable space of inbreeding coefficients is considerably enlarged. Fig. 3 shows the attainable space of non-equilibrium populations, wherein the trajectories traversed towards inbreeding equilibrium is shown, assuming initially outbred popula- tions and constant rates of selfing. In fig. 3(a), where all selfing is intergametophytic, points well outside the allowable equilibrium space (of fig. 2) are reached. In fig. 3(b), where 30 per cent intragametophytic selfing is assumed, a reduction in the attainable space occurs, and a faster approach to equilibrium is evident. With no intergametophytic selfing, equilibrium is reached in the first generation (figure not shown). In general, fig. 3 shows that non-equilibrium populations have a larger allowable space of inbreeding coefficients. However, the total "attainable" space is still less

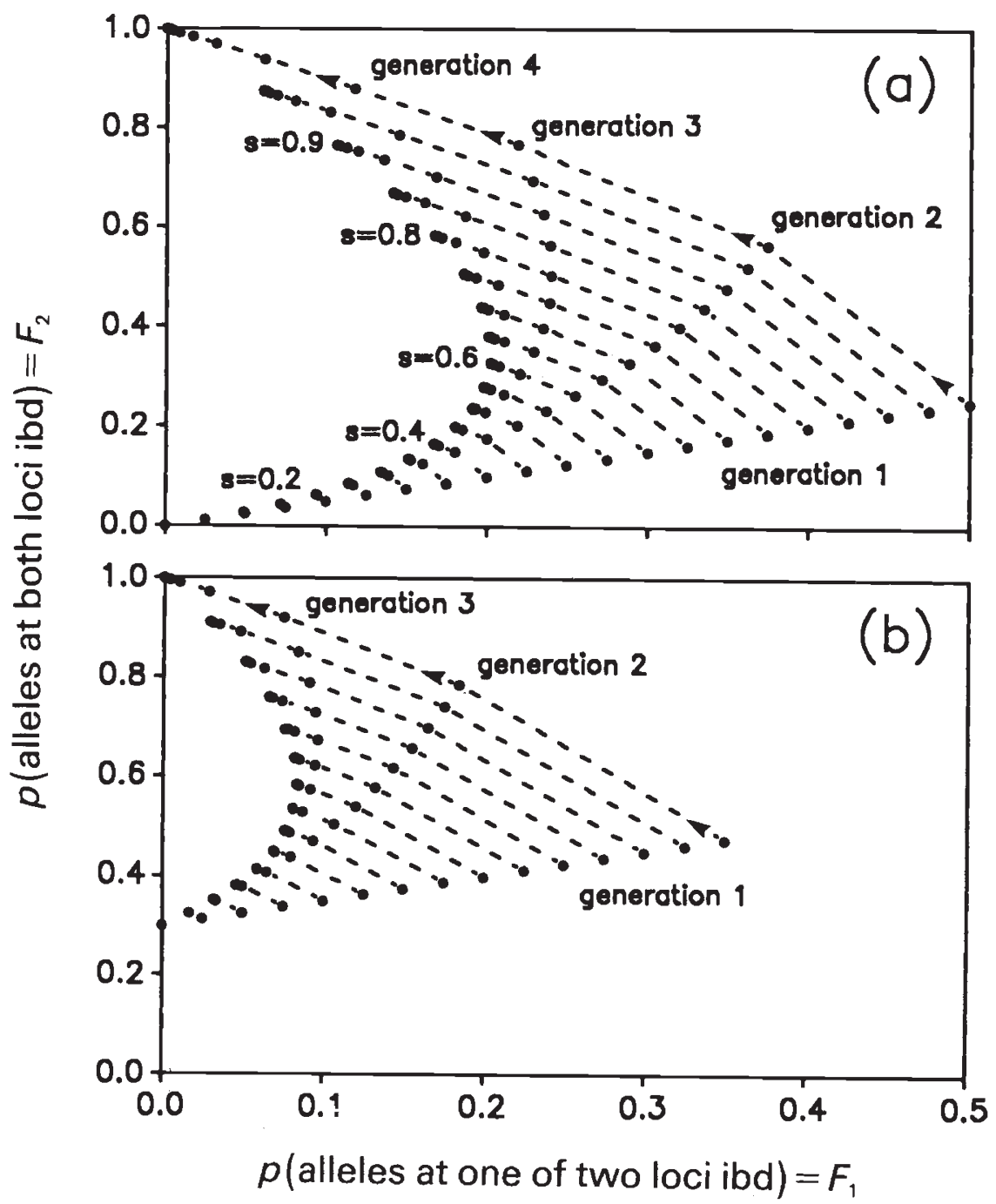

Figure 3 The approach to inbreeding equilibrium of an initially outbred population. (a) For various mixtures of intergametophytic selfing and random outcrossing (no intragametophytic selfing). (b) For mixtures of intergametophytic selfing, random outcrossing and 30 per cent intragametophytic selfing. In general, the attainable space of inbreeding coefficients is greater (but a population with only intragametophytic selfing and random outcrossing will reach equilibrium in one generation, which severely restricts this space.) 
than the total space, and any estimated values of inbreeding coefficients which lie outside the attainable space would indicate other sources of inbreeding, most likely population substructure.

\section{(iii) Estimators for the two-locus inbreeding coefficients}

How can these inbreeding coefficients, and hence the selfing rates, be estimated from genotypic frequencies? Herein, we derive the simplest estimators for inbreeding coefficients, which are functions of two-locus heterozygosities. First note that for alleles $i$ and $j$ at the first locus, and alleles $k$ and $l$ at a second locus, the inbreeding coefficients specify the genotypic frequencies $f_{i j k l}$ at the two unlinked loci as

$$
f_{i j k l}=\left\{\begin{array}{cc}
F_{0} p_{i}^{2} p_{k}^{2}+F_{1} p_{i} p_{k}\left(p_{i}+p_{k}\right) / 2 \\
\quad+F_{2} p_{i} p_{k} & (i=j, k=l) \\
2 F_{0} p_{i} p_{j} p_{k}^{2}+F_{1} p_{i} p_{j} p_{k} & (i \neq j, k=l) \\
2 F_{0} p_{i}^{2} p_{k} p_{l}+F_{1} p_{i} p_{k} p_{l} & (i=j, k \neq l) \\
4 F_{0} p_{i} p_{j} p_{k} p_{l} & (i \neq j, k \neq l) .
\end{array}\right.
$$

From equation (4), two-locus heterozygosities can be obtained. For example, to specify the fraction of a population heterozygous at neither locus, the above frequencies $f_{i j k l}$ are summed over all $i, j, k, l$ all for $i=j$ and $k=l$. Doing similar operations gives the frequencies of individuals heterozygous at 0,1 , and 2 loci, denoted $H_{0}, H_{1}$, and $H_{2}$ respectively, as

$$
\begin{aligned}
& H_{0}=F_{0} J_{A} J_{B}+\frac{1}{2} F_{1}\left(J_{A}+J_{B}\right)+F_{2} \\
& H_{1}=F_{0}\left(J_{A}+J_{B}-2 J_{A} J_{B}\right)+\frac{1}{2} F_{1}\left(2-J_{A}-J_{B}\right) \\
& H_{2}=F_{0}\left(1-J_{A}-J_{B}+J_{A} J_{B}\right),
\end{aligned}
$$

where $J_{A}$ and $J_{B}$ are the expected homozygosities at locus $A$ and $B$, respectively (these are obtained by summing the squared gene frequencies).

From equation (5), the two-locus inbreeding coefficients are related to the two-locus observed heterozygosities and single-locus expected homozygosities as

$$
\begin{aligned}
& F_{0}=\left(\frac{H_{2}}{\left(1-J_{A}\right)\left(1-J_{B}\right)}\right) \\
& F_{1}=2\left(\frac{H_{1}-F_{0}\left(J_{A}+J_{B}-2 J_{A} J_{B}\right)}{\left(2-J_{A}-J_{B}\right)}\right) \\
& F_{2}=1-F_{0}-F_{1} .
\end{aligned}
$$

Once one has these estimates of the $F_{i}$, one can obtain estimates of the selfing rates $r$ and $s$ with equation (3).
The above are "method-of-moments" estimators. It is possible to formulate a more efficient, maximum likelihood estimation procedure for $r$ and $s$, but this involves much more algebra, as well numerical methods to solve the likelihood function (see Ritland, 1986).

\section{(iv) Selfing rates in two fern species}

A wide variety of selfing rates has been found in homosporous ferns (reviewed in D. Soltis and P. Soltis, 1987a). The most statistical power to make inferences about selfing rates occurs at intermediate selfing levels; unfortunately, few populations show intermediate selfing rates, and those are either small populations or have few polymorphic loci. The one species that has clear mixed-mating, Dryopteris expansa (D. Soltis and P. Soltis, 1987b), was polymorphic for just one locus, precluding application of our procedure.

To illustrate how the estimators developed in this paper can be used, we draw upon data used in two earlier studies: (1) Botrychium virginianum, an inbreeder (D. Soltis and P. Soltis, 1986) and (2) Polystichum munitum, an outbreeder (P. Soltis and D. Soltis, 1987), to which the reader is referred for details not given here. Both studies are based upon three populations, and the populations, the number of individuals sampled, and the number of loci that were polymorphic (95 per cent criterion), are given in table 1 .

A computer program was written to implement the estimation procedure (it is available from K.R. upon receipt of a DOS formatted floppy diskette). If more than two polymorphic loci were present, observed and expected heterozygosities were obtained as averages over all possible pairs of loci. The statistical distribution of estimates was obtained by performing 100 bootstraps (bootstrapping is the procedure whereby replicate dataset are created by sampling observations from the original dataset with replacement; the distribution of estimates among replicate datasets represents the estimation variance).

The estimates of two-locus $F$ values and selfing rates obtained from these $F$ values are given in table 1. Although estimates of one-locus $F$ ( = $\left.\frac{1}{2} F_{1}+F_{2}\right)$ matched those of earlier studies, most joint estimates of selfing rates were at the extreme values of $-1 \cdot 0$ or $2 \cdot 0$. These are possible if statistical error is great, and indeed, the estimates fluctuated widely among bootstraps, indicative of the error of these estimates. All the estimates of $F$ values were outside the allowable space for equilibrium populations (fig. 2), but their 95 percent 
Table 1 Estimates of two-locus inbreeding coefficients and mating system parameters for three populations of an inbreeding fern and for three populations of an outbreeding fern. The number of individuals (Ind.) assayed and the number of polymorphic loci (Loci) are also given, as is the estimate of the one-locus inbreeding coefficient, $F$

\begin{tabular}{|c|c|c|c|c|c|c|c|c|c|}
\hline \multirow{2}{*}{$\begin{array}{l}\text { Species/ } \\
\text { Population }\end{array}$} & \multirow{2}{*}{$\begin{array}{l}\text { No. } \\
\text { Ind. }\end{array}$} & \multirow{2}{*}{$\begin{array}{l}\text { No. } \\
\text { Loci }\end{array}$} & \multirow[b]{2}{*}{$\hat{F}$} & \multicolumn{3}{|c|}{ Two-locus $F$ values } & \multicolumn{3}{|c|}{ Mating system rates } \\
\hline & & & & $\hat{F}_{0}$ & $\hat{F}_{1}$ & $\hat{F}_{2}$ & $\hat{t}$ & $\hat{s}$ & $\hat{r}$ \\
\hline BREID & 50 & 2 & $0.96^{*}$ & 0.00 & 0.09 & $0.91^{*}$ & 0.00 & $2 \cdot 00$ & $-1 \cdot 00$ \\
\hline BIGROCK-R & 73 & 3 & $0.93 *$ & 0.00 & $0 \cdot 15^{2}$ & $0.85^{*}$ & 0.00 & $2 \cdot 00$ & $-1 \cdot 00$ \\
\hline BIGROCK-T & 50 & 3 & $0.95^{*}$ & 0.00 & $0 \cdot 10$ & $0.91^{*}$ & 0.00 & $2 \cdot 00$ & $-1 \cdot 00$ \\
\hline GORGE-1 & 140 & 8 & -0.02 & $1 \cdot 00$ & $-0 \cdot 16$ & 0.06 & $1 \cdot 19$ & -0.33 & $0 \cdot 15$ \\
\hline GORGE-2 & 81 & 7 & 0.00 & 1.07 & $-0 \cdot 14$ & 0.07 & $1 \cdot 16$ & -0.31 & $0 \cdot 16$ \\
\hline NFCW & 60 & 8 & 0.09 & $0.79^{3}$ & $0 \cdot 25^{1}$ & -0.03 & $0.69^{3}$ & $0.48^{1}$ & -0.17 \\
\hline
\end{tabular}

\footnotetext{
* Less than 1.0 at 95 per cent confidence level.

${ }^{1} p \cong 0.86$ for true value $>0.0$.

${ }^{2} p \cong 0.92$ for true value $>0.0$.

${ }^{3} p \cong 0.90$ for true value $<1 \cdot 0$.
}

confidence intervals did reach within this space. Loci with greater polymorphism, or greater sample sizes, are needed to reduce the statistical error of these estimates.

If one assumes that no intergametophytic selfing is taking place in these populations, then the one-locus $F$ is sufficient to estimate the intragametophytic selfing rate. This one-locus $F$ is much more likely to show statistical significance, and indeed, the one-locus $F$ for the Botrychium populations all differed significantly from one (table 1). By contrast, joint estimates of $s$ and $r$ were non-significant (table 1). This illustrates the tradeoff between model complexity and statistical information.

Interestingly, in one population of each species, the estimates of the two-locus coefficient $F_{1}$ were marginally significantly greater than zero. $F_{1}$ can be non-zero only if intergametophytic selfing is occurring, thus its non-zero value is the major clue indicating intragametophytic selfing in these populations.

\section{DISCUSSION AND CONCLUSIONS}

Although the estimation procedure presented in this paper is a relatively straightforward method for studying an important problem, there are three problems that limit its practical use. First, natural populations for some fern species are often very small, consisting of a few genets. Second, the assumption of inbreeding equilibrium is of unknown validity. Third, a low level of genetic variation at the marker loci can severely limited the power to detect intergametophytic selfing.
Although the number of genets or individuals can be quite large in some populations of ferns (e.g., Polystichum munitum and Blechnum spicant), populations of other species (e.g., Cheilanthes gracillima and some populations of Botrychium virginianum and Dryopteris expansa) have only $50-100$ individuals. Lycopods, in addition to small population size, have the additional complication of vegetative reproduction, which further limits the effective number of individuals one can sample ( $P$. Soltis and D. Soltis, 1988b). However, unless the population size is very small, this is not a problem for if the number of sampled genets at least the minimum for adequate estimation of gene frequency ( $c a .25$ ), one can increase the effective sample size by increasing the number of loci assayed, rather than the number of individuals, provided that additional polymorphic loci can be found, as discussed below.

The assumption of inbreeding equilibrium does limit the confidence one can place on any joint estimates of the two selfing rates. We note that an alternative and more powerful multilocus method for detecting the presence of intergametophytic selfing, which does not assume inbreeding equilibrium, can be derived as follows. It was noted earlier that if the two-locus coefficient $F_{1}$ is positive, then intergametophytic selfing must be present. Marginal evidence existed for a positive $F_{1}$ in two populations (table 1). We can extend this reasoning to $n$ independent loci. If a population practises a mixture of intragametophytic selfing and random mating (no intergametophytic selfing), then genotypes are either ibd at all loci with probability $F$, or not-ibd (at Hardy-Weinberg expectations for each locus) with probability $1-F$. Under 
this null hypothesis, the expected frequency of genotype $l$, with alleles $i$ and $j$ at locus $k(k=$ $1, \ldots, n)$ is

$$
f_{l}=F \prod_{k} \delta_{i j} p_{i k}+(1-F) \prod_{k}\left(2-\delta_{i j}\right) p_{i k} p_{j k}
$$

where $\delta_{i j}=1$ if $i=j$ and $\delta_{i j}=0$ if $i \neq j$ (and assuming independent loci). If this expected frequency does not match the observed frequency, as tested by a goodness-of-fit test, then the alternative hypothesis of intergametophytic selfing would be accepted.

The most severe limitation encountered however has been the level of genetic variation at isozyme loci. The higher-order inbreeding coefficients needed to detect intergametophytic selfing require a correspondingly higher level of genetic variation for good detection. Although the level of variation currently detected by starch-gel electrophoresis has been sufficient to demonstrate intragametophitic selfing (assuming intergametophytic selfing is not present), further resolution of the fine-structure of mating systems and genetic structure in homosporous cryptograms will either require a search for additional polymorphic isozyme loci or the development of restriction fragment length polymorphism (RFLP) markers.

In conclusion, the presence of intergametophytic selfing would indicate that populations of homosporous pteridophytes are probably subdivided into neighbourhoods of related individuals. This could be particularly true for inbreeding populations, as it is expected that if intragametophytic selfing is frequent, then spatial family structure or spatial patchiness of genotypes is more likely to occur (P. Soltis and D. Soltis, $1988 a$ ). In outbred populations where genotypic frequencies are at Hardy-Weinberg (such as Polystichum munitum or Blechnum spicant, P. Soltis and D. Soltis, 1988a), one can make the clear, indirect inference that patchiness is minimal, and probably that intrapopulation spore dispersal is extensive. In populations with significant levels of gene fixation, such as Cheilanthes gracilima, the extent of substructure needs more direct study. This can involve studies of spore dispersal, which follow the fate of individual spores, or studies of the spatial autocorrelation of gene frequencies and the local clustering of genotypes.

Because intergametophytic selfing is a milder form of inbreeding than intragametophytic selfing, progeny derived from intergametophytic selfing should show less inbreeding depression (Hedrick, 1989). Indeed, in Gymnocarpium dryopteris ssp. disjunctum, inbreeding depression is greater in iso- lated gametophytes, which self intragametophytically, than in sib pairs of gametophytes, which self intergametophytically (Kirkpatrick, 1988; P. Soltis and D. Soltis, 1990). The differential strength of these two forms of inbreeding would affect the progress of selection against deleterious alleles, and hence the evolution of inbreeding depression in ferns.

Acknowledgements This work was supported by grants from the Natural Sciences and Engineering Research Council of Canada and the National Science Foundation of USA (grants BSR-8516721 and BSR-8620444).

\section{REFERENCES}

COCKERHAM, C. C. AND WEIR, B. S. 1973. Descent measures for two loci with some applications. Theor. Pop. Biol., 4, 300-330.

HEDRICK, P. 1987. Population genetics of intragametophytic selfing. Evolution, 41, 137-144.

HEDRICK, P. 1989. The mating system and evolutionary genetics. In Wohrman, K. and Jain, S. (eds). Population Biology and Evolution. Springer-Verlag, Berlin.

HOLSINGER, K. E. 1987. Gametophytic self-fertilization in homosporous plants: development, evaluation, and application of a statistical method for evaluating its importance. Am. J. Bot., 74, 1173-1183.

KIRKPATRICK, R. E. B. 1988. An analysis of the mating system of Gymnocarpium dryopteris ssp. disjunctum. M.S. Thesis, Washington State University, Pullman.

KLEKOWSKI, E. J. JR. 1969. Reproductive biology of the Pteridophta. IV. The Blechnaceae. Bot. J. Linn. Soc., 62, 361-377.

KLEKOWSKI, E. J. JR. 1979. The genetics and reproductive biology of ferns. In Dyer, A. F. (ed.) The Experimental Biology of Ferns, Academic Press, London, pp. 133-170.

KLEKOWSKI, E. J. JR. AND BAKER, H. G. 1966. Evolutionary significance of polyploidy in the Pteridophyta. Science, 153, 305-307.

McCAULEY, D. E., WHITTIER, D. P., AND REILLY, L. M. 1985. Inbreeding and the rate of self-fertilization in a grape fern, Botrychium dissectum Am. J. Bot. 72, 1978-1981.

NEI, M. 1986. Definition and estimation of fixation indices. Evolution, 40, 643-645.

RITLAND, K. 1986. Joint maximum likelihood estimation of genetic and mating structure using open-pollinated progenies. Biometrics, 42, 25-43.

SLATKIN, M. 1985. Rare alleles as indicators of gene flow. Evolution, 39, 53-65.

SOLTIS, D. AND SOLTIS, P. 1986. Electrophoretic evidence for inbreeding in the fern Botrychium virginianum (Ophioglossaceae). Am. J. Bot. 73, 588-592.

SOLTIS, D. AND SOLTIS, P. 1987a. Polyploidy and breeding systems in homosporous Pteridophyta: a reevaluation. Am. Nat. 130, 219-232.

SOLTIS, D. AND SOLTIS, P. $1987 \mathrm{~b}$. Breeding system of the fern Dryopteris expansa: evidence for mixed mating. Am. J. Bot. 74, 504-509.

SOLTIS, D., SOLTIS, P. AND NOYES, R. 1988. An electrophoretic investigation of intragametophytic selfing in Equisetum arvense. Am. J. Bot., 75, 231-237. 
SOLTIS, P. AND SOLTIS, D. 1987. Population structure and estimates of gene flow in the homosporous fern Polystichum munitum. Am. J. Bot. 41, 620-629.

SOLTIS, P. AND SOLTIS, D. 1988a. Genetic variation and population structure in the fern Blechnum spicant (Blechnaceae) from Western North America. Am. J. Bot. 75, 37-44.

SOLTIS, P. AND SOLTIS, D. 1988b. Estimated rates of intragametophytic selfing in Lycopods. Am. J. Bot., 75, 248-256.

SOLTIS, P. AND SOLTIS, D. 1990. Evolution of inbreeding and outcrossing in ferns and fern-allies. Pl. Species Biol. (In press).
SOLTIS, P., SOLTIS, D. AND HOLSINGER, K. E. 1988. Estimates of intragametophytic selfing and interpopulational gene flow in homosporous ferns. Am. J. Bot. 75, 1765-1770.

WEIR, B. S. 1968. The Two Locus Inbreeding Function. PhD. Thesis, North Carolina State University, Raleigh, North Carolina.

WERTH, C. R., GUTTMAN, S. I. AND ESHBAUGH, W. H. 1985. Electrophoretic evidence of reticulate evolution in the Appalachian Asplenium complex. Syst. Bot. 10, 184-192.

WRIGHT, S. 1969. Evolution and the Genetics of Populations. Vol. 2. The Theory of Gene Frequencies. University of Chicago Press, Chicago. 